\title{
ORIGINAL ARTICLE \\ International Spinal Cord Injury Skin and Thermoregulation Function Basic Data Set
}

\author{
A-K Karlsson ${ }^{1}$, A Krassioukov ${ }^{2}$, MS Alexander ${ }^{3}$, W Donovan ${ }^{4}$ and F Biering-Sørensen ${ }^{5}$
}

Objectives: To create an International Spinal Cord Injury (SCI) Skin and Thermoregulation Basic Data Set within the framework of the International SCI Data Sets.

Setting: An international working group.

Methods: The draft of the Data Set was developed by a working group comprising members appointed by the American Spinal Injury Association (ASIA), the International Spinal Cord Society (ISCOS) and a representative of the Executive Committee of the International SCI Standards and Data Sets. The final version of the Data Set was developed after review and comments by members of the Executive Committee of the International SCI Standards and Data Sets, the ISCoS Scientific Committee, ASIA Board, relevant and interested international organizations and societies, individual persons with specific interest and the ISCoS Council. To make the Data Set uniform, each variable and each response category within each variable have been specifically defined to promote the collection and reporting of comparable minimal data.

Results: Variables included in the present Data Set are: date of data collection, thermoregulation history after SCl, including hyperthermia or hypothermia (noninfectious or infectious), as well as the history of hyperhidrosis or hypohidrosis above or below level of lesion. Body temperature and the time of measurement are included. Details regarding the presence of any pressure ulcer and stage, location and size of the ulcer(s), date of appearance of the ulcer(s) and whether surgical treatment has been performed are included. The history of any pressure ulcer during the last 12 months is also noted.

Spinal Cord (2012) 50, 512-516; doi:10.1038/sc.2011.167; published online 31 January 2012

Keywords: spinal cord injury; International Data Set; thermoregulation; skin; pressure ulcer

\section{INTRODUCTION}

The loss of supraspinal control of the sympathetic nervous system and the loss of sensation may cause severe long lasting morbidity and might be life-threatening according to the effects on skin and thermoregulation.

The reduced ability to regulate body temperature puts the individual with spinal cord injury (SCI) at risk of both hyperthermia and hypothermia. Fever, hyperthermia and even hypothermia may accompany infections both in the acute and chronic phase of SCI; however, increased temperature without identified etiologies is also seen. ${ }^{1,2}$ Hyperthermia could be a risk following physical activity as well as during a stay in warm surroundings due to the impaired capacity to reduce body temperature by vasodilatation and sweating. ${ }^{3}$ The individual with SCI and especially those with cervical injury is poikilothermic and is at risk of developing hypothermia in low environmental temperature, even though hypothermia may also be seen in normal ambient temperature. ${ }^{4}$ It is known that body temperature differs according to methods of measurement. ${ }^{5}$

Hypohidrosis is usually seen below the level of lesion, whereas hyperhidrosis could be present above as well as below the level of lesion. It may be a sign of an ongoing pathological process such as syringomyelia, autonomic dysreflexia or dyspepsia and may accom- pany micturition and defecation. Hyperhidrosis may also be present without any known cause. ${ }^{6}$

The newly injured as well as those with chronic SCI are at increased risk of developing pressure ulcers. ${ }^{7,8}$ Furthermore, a tendency towards increasing incidence and prevalence of pressure ulcers has been reported. ${ }^{9}$ Impaired sensation with loss of normal signals from the skin and underlying structures is the main risk factor for developing pressure ulcers. However, impaired vasoregulation below level of lesion probably contributes and makes the skin more sensitive to pressure.

In accordance with the goals of the International Spinal Cord Injury Data Sets, ${ }^{10}$ the aim of the Skin and Thermoregulation Function Basic Data Set for SCI is to standardize the collection and reporting of a minimal amount of information on these issues in daily practice. Furthermore, the International SCI Skin and Thermoregulation Function Basic Data Set will make it possible to evaluate and compare results from various published studies on skin and thermoregulation function after SCI.

The International SCI Skin and Thermoregulation Function Basic Data Set is applicable to adult individuals with traumatic or nontraumatic supraconal, conal or cauda equina lesions. To ensure that data are collected in a uniform manner each variable and each response category within variables have been specifically defined.

\footnotetext{
${ }^{1}$ Institute of Neuroscience and Physiology, Sahlgrenska University Hospital, Göteborg, Sweden; ${ }^{2}$ International Collaboration On Repair Discoveries (ICORD), University of British Columbia and Vancouver Coastal Health, Vancouver, British Columbia, Canada; ${ }^{3}$ Renown Rehabilitation Hospital Reno, NV, USA; ${ }^{4}$ University of Texas Health Science Center, Baylor College of Medicine, Houston, TX, USA and ${ }^{5}$ Clinic for Spinal Cord Injuries, NeuroScience Centre, Rigshospitalet, and University of Copenhagen, Copenhagen, Denmark Correspondence: Dr A-K Karlsson, Institute of Neuroscience and Physiology, Sahlgrenska University Hospital, S 41345 Göteborg, Sweden. E-mail: ann-katrin.karlsson@neuro.gu.se
}

Received 1 September 2011; revised 8 November 2011; accepted 11 November 2011; published online 31 January 2012 
The International SCI Skin and Thermoregulation Function Basic Data Set will mostly be used in connection with the background information within the International SCI Core Data Set. ${ }^{11}$ This specifically applies to the documentation of the level, completeness and time post spinal cord lesions, which have an important role on skin and thermoregulation parameters following injury. The International SCI Skin and Thermoregulation Function Basic Data Set may be used once yearly in chronic SCI individuals.

This document was produced under the umbrella of the American Spinal Injury Association (ASIA) and the International Spinal Cord Society (ISCoS).

\section{MATERIALS AND METHODS}

The first draft of the International SCI Skin and Thermoregulation Function Basic Data Set was made by a working group consisting of members appointed by the ASIA and the ISCoS, together with a representative of the Executive Committee of the International Spinal Cord Injury Standards and Data Sets. The developmental process for the International SCI Skin and Thermoregulation Function Basic SCI Data Set followed the steps given below:

1. The working group of the International SCI Skin and Thermoregulation Function Basic Data Set finalized the first draft during a 2 days meeting in Copenhagen in March 2007. This was further elaborated by frequent e-mail contacts between the group members.

2. The Data Set has been reviewed by members of the Executive Committee of the International SCI Standards and Data Sets.

3. The comments from the Committee members were discussed in the working group and appropriate responses were made to the Data Set.

4. Members of the ISCoS Scientific Committee and ASIA Board were also asked to review the Data Set.

5. The comments from the Committee and Board members were discussed in the working group and a response was made, and further adjustments of the Data Set were performed.

6. Relevant and interested scientific and professional international organizations and societies and individuals who were interested were also invited to review the Data Set. In addition, the Data Set was posted on the ISCoS and ASIA websites for over two months to allow comments and suggestions.

7. The comments were discussed and responded to by the working group and when appropriate, adjustments to the Data Set were made.

8. Final approval of the Data Set was performed by the ISCoS Scientific and Executive committees and the ASIA board.

\section{RESULTS}

The International SCI Skin and Thermoregulation Function Basic Data Set is structured according to established protocol for the International SCI Data Sets. ${ }^{10}$ The complete Data Set form is included in the appendix. The complete data syllabus, data sheet and training cases will be available at the respective websites of ISCoS (www.iscos. org.uk) and ASIA (www.asia-spinalinjury.org).

\section{Date of data collection}

As the collection of data on skin and thermoregulation functions may be carried out at any time following SCI, the date of data collection is imperative to compute time since the spinal cord lesion and to identify the data collected in relation to other data collected on the same individual at various time points.

\section{Thermoregulation history after spinal cord lesion within the last 3 months}

This variable will document the thermoregulation and sudomotor history after SCI within the last 3 months. The presence of hyperthermia usually defined as rectal temperature above $38.4{ }^{\circ} \mathrm{C},{ }^{12}$ as well as hypothermia defined as rectal temperature below $35^{\circ} \mathrm{C},{ }^{12}$ may be caused by an infection. Hyper and hypothermia may also be caused by non-infectious reasons as exercise or by increased or decreased environmental temperature; the individual with spinal cord lesion is prone to be poikilothermic.

Hyperhidrosis is defined as excessive sweating above or below level of injury in the absence of increased ambient temperature. Hyperhidrosis may be a sign of an ongoing pathological process, such as syringomyelia, autonomic dysreflexia or dyspepsia, or may accompany micturition and defecation. Hyperhidrosis may also be present without any known cause. ${ }^{6}$ Hypohidrosis is defined as a loss of ability to sweat and is normally seen below the level of injury due to disruption of sympathetic outflow. Hypohidrosis may be total or partial. Other thermoregulation and sudomotor findings (for example, subjective feeling of coldness) may be present and should be specified.

\section{Temperature and time performed}

This variable documents the body core temperature investigated rectally, orally, axillary or in the ear. It should be noted that rectal investigation of body core temperature is most reliable. ${ }^{5}$ Present body temperature at the day of investigation should be documented, and as temperature is affected by the circadian rhythm, the time of evaluation should be reported.

\section{Any pressure ulcer at present}

This variable documents presence of a pressure ulcer, the grade and location of the ulcer at the time of investigation. Other types of skin ulcers are not included here. A pressure ulcer could be present at any time post SCI. One diagram with the location and grade is to be filled in for each pressure ulcer. Pressure ulcers are usually seen on prominent body structures and caused by pressure on the region. The location of the pressure ulcer should be documented including right/left side of the body when applicable. A pressure ulcer is defined by different grades of skin involvement according to the definitions below. ${ }^{13-15}$

Stage I: An observable pressure-related alteration of intact skin whose indicators as compared with an adjacent or opposite area on the body may include changes in one or more of the following: skin temperature (warmth or coolness), tissue consistency (firm or boggy feeling) and/or sensation (pain, itching). The ulcer appears as a defined area of persistent redness in lightly pigmented skin, whereas in darker skin tones, the ulcer may appear with persistent red, blue or purple hues.

Stage II: Partial-thickness skin loss involving epidermis, dermis or both. The ulcer is superficial and presents clinically as an abrasion, blister or shallow crater.

Stage III: Full-thickness skin loss involving damage to or necrosis of subcutaneous tissue that may extend down to, but not through, underlying fascia. The ulcer presents clinically as a deep crater with or without undermining of adjacent tissue.

Stage IV: Full-thickness skin loss with extensive destruction, tissue necrosis or damage to muscle, bone or supporting structures (for example, tendon, joint capsule). Undermining and sinus tracts also may be associated with stage IV pressure ulcers.

Pressure ulcers do not progress from stage I to stage II to stage III and ultimately to stage IV. Rather, they begin deep inside the tissues, close to the bone, and erupt on the surface of the skin. Conversely, healing ulcers do not progress in reverse order of the stages. Muscle tissue is more sensitive than skin to pressure-induced ischemia. $^{13}$ 
Unstageable: Full thickness tissue loss in which the base of the ulcer is covered by slough (yellow, tan, gray, green or brown) and/or eschar (tan, brown or black) in the wound bed. Until enough slough and/or eschar is removed to expose the base of the wound, the true depth, and therefore stage, cannot be determined. ${ }^{14}$

Stage I pressure ulcers are not always accurately assessed, especially in people with darkly pigmented skin.

Size: The size of the ulcer may be difficult to measure accurately, as the opening may be small, whereas there is undermining of the skin below. The ulcer may also be irregular in size. Therefore, we recommend that largest opening diameter, largest diameter, including undermining, smallest opening diameter and largest depth, should be measured, as the size of the pressure ulcer has influence on treatment and time to healing.

\section{Date of appearance of the ulcer}

This variable documents the date of appearance of the ulcer. A pressure ulcer usually presents with a minor alteration to the skin and progresses later. The date of appearance should be the date when the first alteration to the skin was observed. If the date is unknown this should be documented.

\section{Surgical treatment}

This variable documents if the ulcer has been surgically treated. Surgical treatment may include any treatment ranging from small debridement of the surface of the ulcer to rotation flaps. In this context the variable includes major surgical methods such as direct closure, skin grafting or rotation flaps. Minor debridement is defined as conservative treatment and should not be documented.

\section{Any other pressure ulcer during the last 12 months}

This variable documents presence of any pressure ulcers during the last 12 months. The location should be given for each pressure ulcer during the last 12 months. A pressure ulcer could have been present at any time post spinal cord lesion. This variable documents the presence and location of any other pressure ulcer(s) during the period of the last 12 months only.

\section{Surgical treatment of any other pressure ulcer during the last 12 months}

This variable documents if the ulcer has been surgically treated. In this context the variable includes major surgical methods such as direct closure, skin grafting or rotation flaps. Minor debridement is defined as conservative treatment and should not be documented.

\section{DISCUSSION}

The International Spinal Cord Injury Skin and Thermoregulation Function Basic Data Set is thought to be used in conjunction with the International SCI Core Data Set and other autonomic function Data Sets (Cardiovascular, Pulmonary, Endocrine/Metabolic Data Sets). The present Data Set will give additional important information of the effect of autonomic dysfunction on skin and thermoregulation function. The collection of data regarding thermoregulation and sudomotor history, including hyperthermia, hypothermia, hyperhidrosis and hypohidrosis as well as the present body temperature, is important because some of these conditions may be life threatening. The collection of data regarding presence, location, size, grade and surgical treatment of pressure ulcers gives important information regarding a condition that can result in high morbidity. The estimation of size of the ulcer is important as the time to healing depends on the total size including largest and smallest opening diameter, largest diameter, including undermining and depth. However, the presence of a pressure ulcer may also be a sign of other disease and/or reduced capacity to take responsibility for the injured body. ${ }^{16}$ The risk of developing pressure ulcers persists life long, therefore the presence not only of a pressure ulcer today but also during the last 12 months should be noted.

It is extremely important that data be collected in a uniform manner. Furthermore, the use of a standard format is essential for combining and comparing the data from multiple sites. For these reasons, each variable and each response category within each variable have been specifically defined in a way that is designed to promote the collection and reporting of comparable minimal data. Although, the International SCI Skin and Thermoregulation Data Set has been revised by the international community it is expected that this Data Set will require periodic revisions and updates. Ideas for improvement of the Data Set are welcome and should be forwarded to corresponding author.

\section{DATA ARCHIVING}

There were no data to deposit.

\section{CONFLICT OF INTEREST}

The authors declare no conflict of interest

\section{ACKNOWLEDGEMENTS}

Coloplast A/S, Denmark has supported the work with this Data Set with an unconditional grant. We are thankful for comments and suggestions received from Ralph Marino, Susan Charlifue, Gordana Savic, Inge Eriks Hoogland, Jan Groothuis Marcel Post, Inder Perkash, Eric Weerts, Lawrence Vogel and Floris van Asbeck.

1 Dietrich WD, Bramlett HM. Hyperthermia and central nervous system injury. Prog Brain Res 2007; 162: 201-217.

2 McKinley W, McNamee S, Meade M, Kandra K, Abdul N. Incidence, etiology and risk factors for fever following acute spinal cord injury. J Spinal Cord Med 2006; 29: 501-506

3 Price MJ. Thermoregulation during exercise in individuals with spinal cord injuries. Sports Med 2006; 36: 863-879.

4 Khan S, Plummer M, Martinez-Arizala A, Banovac K. Hypothermia in patients with chronic spinal cord injury. J Spinal Cord Med 2007; 30: 27-30.

5 Sund-Levander M, Forsberg C, Wahren LK. Normal oral, rectal, tympanic and axillary body temperature in adult men and women: a systematic literature review. Scand J Caring Sci 2002; 16: 122-128.

6 Andersen LS, Biering-Sorensen F, Muller PG, Jensen IL, Aggerbeck B. The prevalance of hyperhidrosis in patients with spinal cord injuries and the evaluation of the effect of dextropropoxyphene hydrochloride in therapy. Paraplegia 1992; 30: 184-191.

7 Frankel H, Sperry J, Kaplan L. Risk factors for pressure ulcer development in the best practice surgical intensive care unit. Am Surg 2007; 73: 1215-1217.

8 Garber SL, Rintala DH. Pressure ulcer in veterans with spinal cord injury: a retrospective study. J Rehabil Res Dev 2003; 40: 433-441.

9 Chen Y, Devivo MJ, Jackson AB. Pressure ulcer prevention in people with spinal cord injury: age-period-duration effects. Arch Phys Med Rehabil 2005; 86: 1208-1213.

10 Biering-Sørensen F, Charlifue S, DeVivo M, Noonan V, Post M, Stripling T et al. International spinal cord injury data sets. Spinal Cord 2006; 44: 530-534.

11 DeVivo M, Biering-Sørensen F, Charlifue S, Noonan V, Post M, Stripling T et al. International spinal cord injury core data set. Spinal Cord 2006; 44: 535-540.

12 Collins KJ. Temperature regulation and the autonomic nervous system. In: Mathias CJ, Bannister R (eds). Autonomic Failure a Textbook of Clinical Disorders of the Autonomic Nervous System. Oxford University Press, Oxford, 1999, pp 92-99.

13 Consortium for Spinal Cord Medicine. The Pressure Ulcer Prevention and Treatment Following Spinal Cord Injury Clinical Practice Guideline. Consortium for Spinal Cord Medicine, Paralyzed Veterans of America, 2000, pp 9-10.

14 Cuddigan J, Frantz RA. Pressure ulcer research: pressure ulcer treatment. A monograph from the national pressure ulcer advisory panel. Adv Wound Care 1998; 11: 294-300.

15 National Pressure Ulcer Advisory Panel (NPUAP) Pressure Ulcer Stages revised, 2007, http://www.npuap.org/pr2.htm.

16 Krause JS, Vines CL, Farley TL, Sniezek J, Coker J. An exploratory study of pressure ulcers after spinal cord injury: relationship to protective behaviors and risk factors. Arch Phys Med Rehabil 2001; 82: 107-113. 


\section{APPENDIX 1}

INTERNATIONAL SPINAL CORD INJURY DATA SETS

SKIN AND THERMOREGULATION FUNCTION BASIC DATA SET

- DATA FORM (Version 1.0)

Date of data collection: YYYYMMDD $\square$ Unknown

Thermoregulation and sudomotor history after spinal cord lesion within the last three months:

$\begin{array}{ll}\square \text { Hyperthermia } & \square \text { Non infectious } \\ & \square \text { Infectious } \\ & \square \text { Unknown } \\ \square \text { Hypothermia } & \square \text { Non infectious } \\ & \square \text { Infectious } \\ & \square \text { Unknown } \\ \square \text { Hyperhidrosis } & \square \text { Above lesion } \\ & \square \text { Below lesion } \\ \square \text { Hypohidrosis } & \square \text { Above lesion } \\ \text { Other, specify } & \square \text { Below lesion }\end{array}$

$\square$ Unknown

Objective measures:

Time performed: HHMM $\square$ Unknown

Temperature:

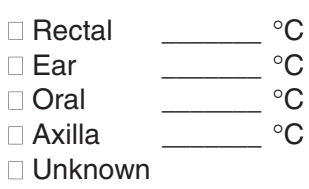

Any pressure ulcer at present: $\quad \square$ Yes $\quad \square$ No $\quad \square$ Unknown

If yes,

Fill in one diagram for each ulcer, by indicating the ulcer stage (I, II, III, IV, Unstageable)) at the appropriate location.

\begin{tabular}{|l|l|l|l|l|l|l|l|}
\hline & Right & Mid-line & Left & $\begin{array}{l}\text { Largest opening } \\
\text { diameter } \\
\mathrm{mm}\end{array}$ & $\begin{array}{l}\text { Largest } \\
\text { diameter, incl. } \\
\text { undermining } \\
\mathrm{mm}\end{array}$ & $\begin{array}{l}\text { Smallest } \\
\text { opening } \\
\text { diameter } \\
\mathrm{mm}\end{array}$ & $\begin{array}{l}\text { Depth } \\
\mathrm{mm}\end{array}$ \\
\hline Occiput & & & & & & & \\
\hline Ear & & & & & & & \\
\hline Scapula & & & & & & \\
\hline Elbow & & & & & & \\
\hline Ribs & & & & & & \\
\hline Spinous process & & & & & & & \\
\hline Iliac crest & & & & & & \\
\hline Sacral & & & & & & \\
\hline Ischial tuberosity & & & & & & & \\
\hline Trochanter & & & & & & & \\
\hline Genitals & & & & & & & \\
\hline Knee & & & & & & & \\
\hline Malleolus & & & & & & & \\
\hline Heel & & & & & & & \\
\hline Foot & & & & & & & \\
\hline Other location & & & & & & & \\
\hline
\end{tabular}

Date of appearance of the ulcer: YYYYMMDD

Has the ulcer been surgically treated: $\square$ Yes $\square$ No If yes, date of last surgical intervention: YYYYMMDD
Unknown

$\square$ Unknown 
Any other pressure ulcer during the last 12 months: $\square$ Yes

If yes,

Fill in one diagram for each ulcer, with tick of the location:

\begin{tabular}{|l|l|l|l|}
\hline & Right & Mid-line & Left \\
\hline Occiput & & & \\
\hline Ear & & & \\
\hline Scapula & & & \\
\hline Elbow & & & \\
\hline Ribs & & & \\
\hline Spinous process & & & \\
\hline Iliac crest & & & \\
\hline Sacral & & & \\
\hline Ischial tuberosity & & & \\
\hline Trochanter & & & \\
\hline Genitals & & & \\
\hline Knee & & & \\
\hline Malleolus & & & \\
\hline Heel & & & \\
\hline Foot & & & \\
\hline Other location & & & \\
\hline
\end{tabular}

Has the ulcer been surgically treated: $\square$ Yes $\square$ No If yes, date of last surgical intervention: YYYYMMDD 